\title{
1 Estimation of the propensity for sexual selection in a 2 cyclical parthenogen
}

3

4 David Duneau ${ }^{1,2,3,8}$, Florian Altermatt ${ }^{4,5,6}$, Jean-Baptiste Ferdy ${ }^{1}$, Frida Ben-Ami ${ }^{4,7}$, Dieter Ebert ${ }^{2,4}$

$6 \quad{ }^{1}$ Université Toulouse 3 Paul Sabatier, CNRS, UMR5174, EDB (Laboratoire Évolution \& Diversité

7 Biologique); Toulouse, France

$8{ }^{2}$ University of Basel, Department of Environmental Sciences, Zoology, Vesalgasse 1, 4051 Basel,

$9 \quad$ Switzerland

$10{ }^{3}$ Instituto Gulbenkian de Ciência, Rua da Quinta Grande 6, 2780-156 Oeiras, Portugal

$11{ }^{4}$ Tvärminne Zoological Station, University of Helsinki, Hanko, Finland.

$12{ }^{5}$ Eawag: Swiss Federal Institute of Aquatic Science and Technology, Dübendorf, Switzerland

$13{ }^{6}$ Department of Evolutionary Biology and Environmental Studies, University of Zürich, Zürich,

14 Switzerland

$15{ }^{7}$ School of Zoology, George S. Wise Faculty of Life Sciences, Tel Aviv University, Tel Aviv, Israel

$17 \quad{ }^{8}$ Corresponding author: david.duneau@gmail.com

Short title: Sexual selection in Daphnia

21 As the manuscript is in preprint in BioRxiv, "The authors wish to be identified to the reviewers." 


\section{Abstract}

23 Cyclical parthenogenesis is a widespread reproductive strategy in which organisms go through one or

24 multiple rounds of clonal reproduction before sexual reproduction. Because sexual reproduction is

25 typically less common than parthenogenesis in populations of the planktonic cladoceran Daphnia

26 magna, it is not frequently studied. Here we examine the sexual process of D. magna and its relation

27 to sexual selection in Daphnia rockpool populations by observing natural mating in these shallow

28 habitats where sex generally occurs throughout the summer. Although microsatellite markers were

29 found to reveal no evidence of disassortative mating or, thus, of inbreeding avoidance, body length

30 and infection status did reveal assortative mating, suggesting sexual selection to act. When two males

31 mated with a single female, the larger male was observed to remain longer, possibly giving it an

32 advantage in sperm competition. Indirect evidence points at the brood pouch as the likely site of

33 fertilization and thus, sperm competition. Sperm length was as variable within ejaculates as it was

34 among males from different populations. Our data provide firm evidence that sexual selection is

35 present in this species, most likely manifesting itself through a combination of female choice and

36 male-male competition. 


\section{Introduction}

38 Whenever sexual reproduction occurs, sexual selection operates to varying degrees on the ability to fertilize (Andersson 1994; Shuker 2010; Clutton-Brock 2017). Sexual selection generally acts on traits that evolve jointly but separately in each sex: For females this means female choice (for males or sperm), and for males this means traits that allow them to gain a competitive advantage either directly against each other or in the face of female choice. Females tend to choose for characteristics that maximize the success of their progeny, such as male vigor, size, ornament, and infection status. Males, on the other hand, tend to increase their mating success with condition-dependent traits, such as mate searching intensity, fighting ability, sperm quality or some types of exaggerated morphological characters (Andersson 1994; Morehouse 2014; Kaldun and Otti 2016; Houslay et al. 2017). Sexual selection thus has the potential to reduce mutation load—one of the frequently cited reasons why, despite its cost, it is maintained (Whitlock and Agrawal 2009; Lumley et al. 2015). In fact, the potential evolutionary benefits of sexual selection probably explain why organisms with sole asexual reproduction are extremely rare. cyclical parthenogenesis. Examples are found in many taxa: aphids, stick insects, rotifers, parasitic nematodes of human, and even vertebrates (Hand 1991; Lampert 2009). In freshwater cladocerans from the genus Daphnia, periods of asexual reproduction are punctuated by sexual reproduction.

These model crustaceans have played an important role in helping us understand fundamental 1884), the definition of germ line and soma (Weismann 1893), phenotypic plasticity (Wolterek 1909), the capacity of natural populations to genetically adapt to anthropogenic stressors (Jansen et al. 2011), parasite local adaptation (Reger et al. 2018), host-parasite coevolution (Decaestecker et al. 2007; 

fertilization, has largely been unexplored, and evidence for sexual selection in this genus has, to our knowledge, never been presented. The few studies that address sexual reproduction in Daphnia have been limited to laboratory conditions and have used different species with seemingly different ecologies (Brewer 1998; Winsor and Innes 2002; Wuerz et al. 2017). We argue that understanding sexual reproduction in cyclical parthenogenetic species such as Daphnia offers the opportunity to study the evolution of traits that are presumably under sexual selection after periods of clonal reproduction.

In Daphnia, sexual reproduction is linked to dormancy, as the two sexual eggs are protected by a hard melanized case known as an ephippium that allows embryos in developmental arrest to survive summer draughts and winter freezes. Sexual reproduction is key to the long-term persistence of Daphnia populations in unstable environments, creating genetically diverse egg-banks from which future populations are established. The frequency of sexual reproduction correlates with habitat instability at a continental scale (Roulin et al. 2013). are believed to be genetically identical (Hebert and Ward 1972), although their morphologies and swimming behaviors differ corresponding to their respective reproductive roles (Brewer 1998; Ebert 2005; Wuerz et al. 2017). Differences between the sexes is based on Darwin's theory of sexual selection (Darwin 1871; Shine 1979; Clutton-Brock 2017) or on selection by intraspecific niche divergence (Cox and Calsbeek 2010; Law and Mehta 2018). As there is no indication that niches diverge between sexes in Daphnia, sexual selection may be the main factor that acts on sexually dimorphic traits; however, little is known about mating in Daphnia. Unlike copepods, (Lonsdale et al. 1998), there is no evidence that males use sex pheromones to find their mates (Crease and Hebert 1983; Winsor and Innes 2002), even though Daphnia respond behaviorally and phenotypically to several chemical cues such as fish kairomones (Hahn et al. 2019). Still, male swimming behavior seems to be optimized for finding an appropriate mate (Brewer 1998), and mating is not random, as 
90

91

92

93

94

95

96

males capture sexually active females (i.e. females carrying ephippial egg cases) more often than they capture other males or asexual females (Brewer 1998; Winsor and Innes 2002). Thus, it seems plausible that couples form in response to certain criteria, possibly reflecting individual quality. There is tremendous variation among Daphnia species in mating duration (from a few seconds up to a day (Forró 1997)), probably because the genus is believed to be older than 140 million years (Cornetti et al. 2019), predating the placental mammal diversification (Springer et al. 2003). Hence, it is difficult to generalize from one species to another. Here, we looked at the sexual interactions of males and females_-from mate finding to the release of the fertilized resting egg —in natural populations of Daphnia magna. Our data provides evidence that sexual selection is present in this species and that it likely manifests itself in a combination of female choice and male-male competition.

\section{Materials and methods}

Study area. We studied a metapopulation of Daphnia magna on the coast of the Baltic Sea in

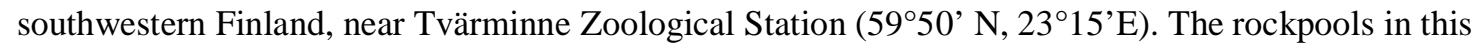
metapopulation are small (average volume about $300 \mathrm{~L}$ ) and shallow (10 to $60 \mathrm{~cm}$ deep) (Altermatt and Ebert 2010), allowing easy access to every part of the habitat. About $40 \%$ of them are inhabited with at least one Daphnia species (Pajunen 1986). Our fieldwork was performed over the course of four summers (2003, 2009, 2010 and 2011) and included 33 rockpool populations (See supplementary material 1 for further information).

Data collection. To estimate the sex ratio in populations, we randomly collected planktonic D. magna with handheld nets (mesh size $0.3 \mathrm{~mm}$ ) or from $1 \mathrm{~L}$ samples of water. The shallow pools allowed us to search and collect mating pairs with wide-mouth pipettes. Mating pairs were then kept separately in 25-mL jars and observed in 1-minute intervals. We recorded the number of males concomitantly attached to the female, the time period until male detachment from the female and the order of detachment when there was more than one male. Using a field dissecting scope, we observed the females and recorded the time post mating until they laid the sexual eggs in the brood pouch, which by this time had already assumed the typical shape of a resting egg case. Females were then kept in the 
116 jars until they dropped the resting egg case. Only males with an open chest (i.e. sign of being adult)

117 were considered in the study. Females are more difficult to classify as adults but we discarded very

118 small individuals to avoid none reproductive individuals. We measured body- and spine-length before

119 checking for parasites under a microscope or storing them in ethanol at $-20{ }^{\circ} \mathrm{C}$.

120 The parasite we looked for was Hamiltosporidium tvarminnensis, a microsporidium commonly, but

121 not exclusively, found in the studied metapopulation (Haag et al. 2011; Goren and Ben-Ami 2013).

122 Although it infects several Daphnia species, its success and pathogenicity are very host specific

123 (Vizoso and Ebert 2005; Sheikh-Jabbari et al. 2014; Urca and Ben-Ami 2018; Orlansky and Ben-Ami

124 2019). It has a mixed mode of transmission—either vertically or horizontally, when spores are

125 released from the decaying cadaver (Lass and Ebert 2006).

126 To measure sperm length, we exposed males to a $1 \%$ nicotine solution, which stimulates muscle

127 contractions, thereby causing a release of sperm (as in Duneau et al. 2012). As only mature sperm are

128 in the testicular lumen (p. 11 in Wingstrand, 1978; p 277 in Zaffagnini, 1987), this method is better

129 than crushing males, which would yield immature sperm of various length. Using a camera mounted

130 on a microscope (magnification 200x), we then photographed and measured the longest length of

131 several sperm in the sample with ImageJ (version 1.50i).

132 Genotyping. To genotype individuals, we homogenized them individually in $100 \mu 1$ of Chelex solution 133 and followed a Chelex DNA extraction protocol (Walsh et al. 1991) before performing a PCR on four

134 Daphnia microsatellite markers (see details in supplementary material 1 - section 5). PCR reactions of

$1355 \mu \mathrm{L}$ were set up with the following cycling conditions: $95^{\circ} \mathrm{C}$ for $15 \mathrm{~min}$, followed by 30 cycles of 94

$136{ }^{\circ} \mathrm{C}$ for $30 \mathrm{~s}, 60{ }^{\circ} \mathrm{C}$ for $1.5 \mathrm{~min}, 72{ }^{\circ} \mathrm{C}$ for $1.5 \mathrm{~min}$, and 10 cycles of $94{ }^{\circ} \mathrm{C}$ for $30 \mathrm{~s}, 47^{\circ} \mathrm{C}$ for $1.5 \mathrm{~min}, 72$

$137{ }^{\circ} \mathrm{C}$ for $1.5 \mathrm{~min}$, and a final elongation step of $72{ }^{\circ} \mathrm{C}$ for $10 \mathrm{~min}$. Genotyping was done on an $A B 3130 x \mathrm{l}$

138 Genetic Analyzer (Applied Biosystems) using genescan 500 LIZ size standard (Applied Biosystems).

139 Microsatellite alleles were scored using genemapper Software version 4.0 (ABI Prism).

140 Coefficient of relatedness. Prior to the relatedness analysis, a simulation was performed to assess

141 different estimators of relatedness coefficients $\left(r_{x y}\right)$ and determine the most appropriate estimator for 
142 our dataset. Given the allelic frequencies within the population (from the sample sizes $\mathrm{n}_{\mathrm{Sp1}-5}=264$ and

$\left.143 \mathrm{n}_{\mathrm{SP} 1-6}=262\right), 2,000$ individual genotypes were simulated. From the simulated genotypes, 1,000 pairs

144 (or comparisons between two simulated individuals) were drawn for four relationship categories:

145 unrelated, half-siblings, full-siblings and parent-offspring. Then, $r_{x y}$ was calculated for each pair within

146 those relationship categories using six different estimators (Lynch 1988; Queller and Goodnight 1989;

147 Li et al. 1993; Ritland 1996; Lynch and Ritland 1999; Wang 2002; Milligan 2003) as described

148 in (Wang 2011). All simulations and calculations of $r_{x y}$ for the empirical dataset were conducted using

149 the package related v0.8 (Pew et al. 2015) and the software Coancestry (Wang 2011) implemented in

150 R. We used the Triadic Likelihood method (TrioML) to describe the coefficient of relatedness between

151 mating males and females, as it was the most appropriate for describing the known relatedness in our

152 simulated data. Using it, we compared the coefficient of relatedness of mating individuals to the

153 coefficient of randomly associated male and female pairs from the same population.

Paternity assessment. Based on the genotypes obtained for the coefficient of relatedness, we selected polyandrous matings to assess the paternity of each egg in the ephippia from microsatellites. We performed the same genotyping as above, but on the oocyte.

Statistical analysis. All analyses were performed using R and Rstudio (RStudio Team 2016; R Core Team 2019). Supplementary material 1 was generated by Rmarkdown, a component of RStudio, and provided a summary data table, with all scripts and their associated analyses and plots, including supplementary figures. All the analysis and illustrations were done with the tidyverse R package suite (Wickham 2016; Wickham and Henry 2019; Wickham et al. 2019). We used the Viridis color palette to assure that plots would print well in grey scale and be readable for those with colorblindness (Garnier 2018). To illustrate the difference between factors in paired analysis, we also used the estimation graphic methods followed in Ho et al. (2019) with the package dabestr v0.2.2. This method uses bootstrap to estimate the difference between means and a $95 \%$ confidence interval. Although not perfect to illustrate complex mixed models, it nonetheless helps represent the effect of paired comparison and indicates the level of confidence we can have in it. Odds ratios quantify the relation between two factors and typically quantify the effect of a variable. 
169 Generalized mixed models were fitted using the function fitme from the package spaMM v2.6.1

170 (Rousset and Ferdy 2014). This function allowed us to include random effect in the mixed model

171 whenever necessary, notably to pair the variable by mating or pool it by population (with the argument

172 "1|"), to nest variables (with the argument "/"), to specify the family of the random effect (with the

173 argument "rand.family") and to consider heteroscedasticity (with the argument "resid.model"). The

174 significance of the factors in the model was tested using a likelihood ratio test, which compares the

175 model with and without the variable of interest.

176 Sperm length. Based on AIC criteria, the sperm length was best fitted with a Gamma distribution. In

177 males from the same mating, we tested for difference in sperm length between the first and second

178 male to detach using the model: Sperm_length Position_detached + (1|ID_mating),

179 family=Gamma(link="log"), rand.family= gaussian("identity").

180 In males from several lineages raised in laboratory conditions (AM-AR initially sampled from

181 Armenia, CY-PA-1 from Cyprus, DE-Iinb1 from Germany and RU-KOR-1 from Russia), the model

182 included the differences in variances among clones as follows: Sperm_length $\sim$ Clone $+(1 \mid$ Clone/ID $)$,

183 resid.model= $\sim$ Clone, family= Gamma(link= "log"), rand.family= Gamma(link= "log").

184 As sperm length varied considerably within an ejaculate, we explored this by fitting a gamma or a

185 normal distribution on sperm length data for each individual male using the function fitdist from the

186 package fitdistrplus v1.0.14 (Delignette-Muller and Dutang 2015). We then tested the goodness of fit

187 of this distribution with the function gofstat from the same package. The final AIC for each

188 distribution was obtained by summing the AICs for each male. To test whether there might potentially

189 be two sub-populations of sperms inside one ejaculate, we compared the AIC of the best model to that

190 of a mixed model considering two gaussian distributions. The fit was performed with the function

191 densityMclust from the package mclust v5.4.5 (Scrucca et al. 2016), and the AIC was calculated.

192 Body length. The body length of mating males was best fit with a Gaussian distribution and by

193 considering the difference in variance among populations. To test if there was a difference between

194 males in the same mating, we used the following full model: Body_length as.factor(Nbr_of_males) 
$+(1 \mid$ Population $)$, resid.model $=\sim$ Population, family $=$ gaussian(link=identity $),$ rand.family $=$

The relation between spine and body length of males and females was also best fit with a Gaussian distribution and by considering the difference in variance among populations. To test for a difference between mating and single individuals in the population, we used the following model: Spine_length Body_length + Sex + Mating_status $+(1 \mid$ Population $)$, resid.model $=\sim$ Population, family=gaussian(link=identity). The significance of the factors in the model was tested with a likelihood ratio test, which compares the model with and without "Mating status" as a variable. prevalence in single females was as follows: Sex_ratio Population_size + Prevalence_Female, family= gaussian(link=identity). The significance of the factors in the model was tested using a likelihood ratio test, which compares the model with and without "Prevalence_Female" as a variable. distribution, noting the presence/absence ( 1 vs 0 ) of each individual. "Population" was considered as a random effect in order to pair the analysis. The full model to test for prevalence differences between sexes was as follows: Infectious_status $\sim$ Sex + (1|Population), family=binomial(link="logit"), either with single individuals only or with mating individuals only.

We used the same approach to test for difference in prevalence between mating and non mating individuals, using the full model Infectious_status Mating_status + (1|Population), family=binomial(link="logit"), rand.family= gaussian(link= "identity"), with both sexes analyzed separately. prevalence in males when attached to an infected vs an uninfected female. Population was considered as a random effect to account for prevalence differences among populations, and the ID of the mating pair was nested in the population in order to pair the analysis. The full model to test for assortative 
mating was as follows: cbind(Nbr_inf_M,Nbr_uninf_M) Infection_Female + (1|Pop/ID_mating), family= binomial), rand.family= gaussian (link= identity), where “cbind(Nbr_inf_M,Nbr_uninf_M)" accounts for the number of infected males given the total number of males in the mating.

\section{Results}

\section{Mating formation}

Most of these results were obtained from studies in natural rockpool populations of Daphnia magna.

During the summers when we sampled, the average proportion of males was around $30 \%$, ranging

from 5 to $60 \%$ across populations (Figure 1A). The shallow rockpools of this metapopulation allowed us to capture pairs of mating Daphnia and observe in glass vials the pair's separation, the laying of eggs, and the release of the resting egg cases. Most matings involved one male (i.e. monandrous mating), although matings with two males were also frequent (i.e. polyandrous mating, Figure 1B). In rare cases (seven times out of the 968 matings in the study), we found three males in the same mating. Because our sampling our not totally random, our design did not allow us to estimate the frequency of polyandrous mating per population and consequently, we could not determine what parameters may influence it.

In $80 \%$ of the cases (382/477), we found that mating females showed the typical morphological changes of the brood pouch associated with the formation of a resting egg case (ephippium), suggesting that they were ready to mate. Since relatively few adult females in a population are typically in this transient stage, this finding indicates that mating pairs do not form randomly. However, since D. magna males seem to search for their mates randomly—as opposed to males of the cladoceran Moina brachiate that apparently detect the reproductive status of the females (Forró 1997) - it is therefore likely that, in D. magna as in D. pulicaria (Brewer 1998), females make the choice to accept or escape a mating attempt, and that they are more likely to accept if they are in the appropriate stage of the sexual process. The other $20 \%$ of matings were with non-reproductive females (23/477) or with females reproducing asexually (73/477). If females who are not in sexual 
246 reproduction stage try to escape males, these matings may represent cases where males forced

247 matings, not realizing they would not lead to fertilization success. In the 17 matings with asexually

248 reproducing females for which we recorded mating duration, data, 13 of the males stayed on the

249 females for over 10 minutes (i.e. less than when copulating with appropriate females but still long

250 enough to be considered as more than a simple contact), suggesting that they did not realize that the

251 females were asexual.

Role of body and spina length. To test if formation of mating pairs is mediated by body were on average $2.3 \%$ larger than those randomly caught in the population. For females, this means that older females produce resting eggs. For males, this suggests that larger males are more successful in securing mating. We also found assortative mating regarding body length: larger than average males paired with larger than average females. The strength of this homogamy (15\%, as described by the estimate of the Pearson correlation) is lower than the average strength for size-related homogamy across animal taxa (31\% according to Jiang et al. (2013)) and depends on the population (See supplementary material 1 - section 1.3.3). As larger males may have better access to females, the strength of the homogamy could potentially be lowered by large males also catching small females. Controlling for the average body length of mating males in each population, we also tested whether, males in polyandrous matings tended to be smaller than a single male in a monandrous mating. Males in polyandrous mating were on average $10 \mu \mathrm{m}$ smaller than males in monandrous mating, a tiny and not significant difference (Figure 2B). However, polyandrous matings include males that arrive and attach first to the female, and so could be expected to be about the same length as males in monandrous matings. We thus tested and found that males from polyandrous matings differed in body length (Figure 2C), with the males departing second being on average $1.3 \%$ larger than the first males to detach. This suggests that a larger body length could help the male remain longer on the female,

272 potentially giving it an advantage in competition for egg fertilization. We further tested whether the 
273 length of the tail spine (spina) might influence access to females, specifically whether individuals with

274 longer spines mated more frequently. To do so, we used relative spine length and subtracted the mean

275 value of individuals of the same sex caught randomly in the population. We found that relative spine

276 length was generally shorter for mating individuals (Supplementary material 1 - section 1.3.6).

277 Altogether, these results suggest that body length plays a role in D. magna sexual selection in the

278 rockpool metapopulation.

279 Inbreeding avoidance. The fact that females can potentially choose a particular male offers up the

280 possibility that the species can avoid inbreeding (Duthie and Reid 2016). As inbreeding depression

281 and heterosis have been documented in Daphnia magna, the ability to avoid mating with relatives

282 provides a selective advantage (De Meester 1993; Ebert et al. 2002; Haag et al. 2002). We investigated

283 this inbreeding question in two natural populations by sequencing four polymorphic microsatellites

284 loci (see details in tables in supplementary material 1 - section 4) and testing to see if females mated

285 with more distantly related males less often than chance would expect. The individuals were captured

286 either in the process of mating (Pop SP1-5: 85 females - 147 males; Pop SP1-6: 92 females - 138

287 males) or single (16 males for each population). Our result suggests that individuals that formed

288 mating pairs were not less related than random mating simulated in silico (Wilcoxon test: Pop SP1-5:

$289 \mathrm{~W}=17085, \mathrm{p}=0.6 ;$ Pop SP1-6; $\mathrm{W}=16814, \mathrm{p}=0.17$. See supplementary material $1-$ section 1.4 )

290 suggesting, therefore, that inbreeding avoidance is not part of mate formation.

291 Parasite infections. The prevalence of Hamiltosporidium tvarminnensis, a common microsporidian

292 that infects this metapopulation, averaged around $40 \%$, affecting from 0 to $100 \%$ of individuals of

293 both sexes (Supplementary material 1 - section 1.5.1). Thus, H. tvarminnensis, a parasite that mediates

294 selection in this metapopulation (Cabalzar et al. 2019), was frequent during our study (Ebert et al.

295 2001; Lass and Ebert 2006). Laboratory experiments conducted by Roth et al. (2008) have shown that

296 infected females produce more sons, implying that the parasite's prevalence in a population should

297 correlate positively with the number of males relative the number of females. Contrary to this finding,

298 however, H. tvarminnensis prevalence in single females in our study did not correlate with the sex-

299 ratio in the population (Figure 3A), suggesting that even if individually-infected females produced 
more infected sons, the production of males was compensated at the population level, in accordance with Booksmythe et al. (2018) and that D. magna populations are able to adjust the production of males depending on the current sex-ratio.

Prevalence differed between sexes, but ultimately depended on population and mating status (binomial glm, interaction Sex x Mating status: $\chi^{2} \mathrm{LRT}=17.9, \mathrm{df}=1, \mathrm{p}=0.00002$ ). On average, prevalence was lower in males than females (Figure 3B left panel, odds ratio: 0.64), as suggested in (Roth et al. 2008), but this was reversed in mating pairs (Figure 3B right panel, odds ratio: 1.41), and this result depended strongly on the population.

Parasitism is thought to be a major factor in sexual selection, either because of its direct cost (i.e. females want to avoid becoming infected), or its direct benefits (i.e. healthy males in an infected population might carry good genes). In our study, mating males were infected more often than single males (Figure 3C left panel, odds ratio: 1.85), whereas mating females were infected about equally as often as single females (Figure $3 \mathrm{C}$ right panel, odds ratio $=0.89$ ). This could suggest that females choose infected males, as these males may be particularly strong if they can afford to mate while infected. There was also assortative mating based on infection status: Taking the infection rate of the population and the size of our samples into account, infected males were significantly more likely to mate with infected females than with uninfected ones (Figure 3D, odds ratio: 1.81).

\section{Mating behavior}

After moving mating pairs from the pond to the glass jars, we observed them and recorded the time from the moment of their capture to the moment each male detached (Figure 4). The mean time to detachment was $24 \min ( \pm 1.9 \mathrm{se})$. Assuming that males and females in the process of mating were randomly caught and that mating time is normally distributed, this suggests that the total mating time may be twice as long, i.e. about $50 \mathrm{~min}$. This estimate corroborates with the data we collected on the time until detachment—which ranged from a few to 60 minutes (excluding a unique outlier of 242 min). Polyandrous matings lasted longer than monandrous matings, as the second male remained attached longer, but the first male detached as fast as single mating males. Following male 
detachment, $96 \%$ of females laid their eggs into the brood pouch (Figure 5A), with $86 \%(45 / 52)$ of

\section{Sperm and paternity}

330 Fatherhood analysis. The simultaneous presence of two or more males mounted on the same female

331 is not only a strong indicator for direct male-male competition, but also sperm competition. To

332 explore this facet of the mating, we genotyped the mother, the two attached males, and the two

333 embryos from eight egg cases (ephippia), and found that six of the embryo pairs were fertilized by

334 only one of the males (full-sibs), while the other two embryo pairs were half-sibs.

335 Sperm length. We next investigated whether sperm length contributed to male-male competition

336 (Godwin et al. 2017) and whether differences in sperm morphology and/or quality between males of

337 the same mating could be the substrate for selection upon sperm competition. Looking at 46 polyandrous matings from natural populations, we found differing sperm lengths in males from the same mating (Figure 6A). Although it is difficult to tell whether this difference is biologically relevant, more than $50 \%$ of the simultaneously attached male pairs had a mean difference greater than $0.77 \mu \mathrm{m}$ (i.e. $8.6 \%$ larger than the averaged sperm length). The average sperm length of the second male to detach was 0.96 times the average of the first, a difference that is not statistically significant $\left(\mathrm{df}=1, \mathrm{Chi}^{\wedge} 2 \mathrm{LRT}=2.9, \mathrm{p}=0.086\right)$.

To test for genetic variation in sperm length, we studied the ejaculates of four laboratoryraised D. magna clones and found more variation in sperm length between clones than between individuals from the same genetic background; we also found that some clones had a higher mean

347 sperm length than others (Figure 6B). Considering single ejaculates of males from the rockpools, we

348 found the variation in sperm length within ejaculate to be strikingly large (Figure 6C inlet), ranging from 3 to $20 \mu \mathrm{m}$ with an average of $9 \mu \mathrm{m}$ (Figure 6C). The average standard deviation in sperm length

350 for an ejaculate (i.e. $1.9 \mu \mathrm{m}$ ) was close to the standard deviation calculated for ejaculates across males 351 from three different populations (i.e. $2.2 \mu \mathrm{m}$ ). As large variation in sperm length is often attributed to 
352

different sperm subpopulations, we looked at the distribution in sperm length within each ejaculate (not shown in Figure 6D, which only illustrates the distribution of the pooled sperm length to provide a general idea of sperm length variation) and found that it was better described by a Gamma distribution (Combined AIC per model for each ejaculate was 12096.67) than a Gaussian distribution (Combined AIC per model for each ejaculate was 12218.56) or by a mixture of two Gaussian distributions (Combined AIC per model for each ejaculate was 12613.04). Thus, it is less parsimonious to suggest that ejaculates are composed of a mixture of two morphologies, each with different roles in sperm competition.

\section{Discussion}

Because it is often easier to focus on the asexual part of the life cycle of cyclical parthenogenetic species, the study of the evolution of these species generally concentrates on survival and reproduction (natural selection), without considering the possible role of sexual selection. By working with D. magna populations in shallow rockpools, where sexual reproduction is rather frequent, we were able to focus on the biology of this crustacean's sexual reproduction in a natural setting and to gain an understanding of the role of sexual selection. We were able to conclude that clear evidence exists for sexual selection in cyclical parthenogenetic species. Below we discuss how sexual selection unfolds in the sequential steps of the sexual reproduction process, pointing out the possible mechanisms at work in each step. The entire process is summarized in Table 1.

Mating formation. As with other cyclical parthenogenetic species (Dixon 1977; Ward et al. 1984; Snell and Hoff 1985; Hand 1991), environmental conditions trigger some female Daphnia to switch from producing asexual daughters to producing asexual sons (Ebert 2005). Other females switch from producing asexual daughters to producing sexual eggs that need male fertilization. Males search for appropriate females by swimming quickly in pursuit. Although ,male-female encounters appear to be random, some form of sorting must take place, as mating males are primarily found on females in the late phase of the sexual process, when the structure of the egg case is already visible and oocyte release is imminent. Furthermore, we found evidence of assortative mating for body length and 
infection status, suggesting that, after an initial, presumably random encounter, males either abandon

379 females that do not meet their expectations, or females reject males when they are not at the right stage

380 of reproduction, or when the males do not fit their quality assessment. Typically, even if it may be less strong in cyclical parthenogenetic species than in obligate sexual species, there are more males than females ready to mate in a population at any given time, so males are generally not a limited resource for females, whereas females in the right stage of fertility are more likely to be limited for males. Hence, females are more likely to be choosy, while males are more likely to accept any female, they encounter who is in the right stage of fertility. Consistent with this, we frequently observed females violently shaking off males that attempted to mount them in the rockpool populations (D. Duneau, D. Ebert, personal observation). males in the population. This result was unexpected, as infected males may be weaker and have been shown to have reduced sperm counts (Roth et al. 2008). Females may choose infected males because if

391 they are infected and still able to catch a female, they are likely to be strong. In this case, infection would be an honest signal, a handicap (Zahavi 1975). Alternatively, males may counteract the females' attempts to push them away, with stronger males being more able to resist these rebuffs. This would be consistent with our finding that males in the process of mating are, on average, larger than single males. It is also possible that infected males who are still alive and able to catch females are the strongest males. Since the parasite cannot spread to the female or her offspring during mating, there is no risk associated with mating. Thus, in the mating formation phase of the sexual process, sexual selection, notably for body length, may be driven by female choice.

Copulation. As the density and proportion of sexual animals in a population increase, so too do

400 multiple encounters, with polyandrous matings becoming more common. We observed many cases of 401 polyandrous matings involving two males hooked to one female, and even some cases with three or 402 four males. These matings open the door for two types of male-male competition: First, males may 403 compete directly with each other for the best position and the longest stay-time on a female. We found 404 that the male who stayed on the female longest was, on average, slightly larger than the male who left 
earlier, supporting the theory that stronger males have more control over the situation. Second, males may compete via their sperm. If multiple males deposit their ejaculates around the same time into the female's brood chamber, competition may favor males with more and/or better sperm. Indeed, we found that one male fertilized both eggs in six out of eight cases studied in detail. As D. magna sperm seem non-motile, swimming speed in the brood pouch is likely not a factor in the competition.

410 Fertilization. We observed the following sequence regarding fertilization: Within ten minutes after a 411 male left, most females released one or two eggs into their brood pouches, which, by this time, had 412 developed into the future egg case (ephippium), specialized as a resting structure. The oviducts open 413 into this brood pouch at its caudal end, close to where the male attaches. Fertilization occurs in either 414 the brood pouch (external fertilization) or in the two oviducts (internal fertilization). Although 415 fertilization has never before been studied in D. magna, research on D. pulex has suggested that 416 fertilization occurred internally, before deposition in the brood pouch (Ojima 1958; Hobæk and 417 Larsson 1990). Here we argue, on the contrary, that fertilization in D. magna is most likely external, 418 and that the most plausible mechanism of fertilization is that the male ejaculates a large number of 419 sperm into the brood pouch, and that the oocytes come into contact with this sperm when they enter the brood pouch.

Although future studies are needed to fully test this hypothesis, several arguments support the brood pouch fertilization hypothesis over the internal fertilization hypothesis. First, the genital papilla on the male's abdomen is large and conical shaped, and as such, has rather limited access to the female oviducts; it could not insert itself into the oviduct, which is closed until the eggs are laid (Lee et al. 2019). Second, as each sexual egg is released from one oviduct, males could probably only access one of the oviducts - the one closest to the side they are attached to. This would strongly reduce the possibility that both eggs could be fertilized by only one attached male, and, as both eggs typically hatch, they must both be fertilized. Also, we found that in double matings, the two eggs are often fertilized by the same male, which would not be feasible if the male needed to insert its papilla into each ovary. Third, at least from our observation, the sperm is apparently not motile. It is therefore 
432 streamlined to move in one direction. It ranges from oval to short rod-shaped with two blunt ends

433 (Figure 6D). These facts, taken together, convince us that fertilization inside the oviduct is unlikely in

434 D. magna and that, more likely, the males release their sperm into the brood pouch where they wait for 435 the unfertilized eggs to arrive.

436 How does the sperm meet the oocyte? The brood pouch is part of the outside environment. It 437 is open to the outside, and water can circulate freely through it. Sperm may cover the inner lining of 438 the brood pouch, so that the eggs touch them as soon as they are released from the ovary. Sperm may 439 also preferentially attach to the area surrounding the opening of the oviduct, so they can fertilize the 440 eggs in the moment of their release, although there is no obvious structure supporting this speculation.

441 If this were the case, the first male to attach would have an advantage, and mating may not need to last 442 for $50 \mathrm{~min}$ on average. Another option is that sperm do not attach to any tissue before the eggs arrive 443 but stay suspended in the brood pouch and risk getting flushed out by the stream of water that 444 oxygenates the brood pouch. For fertilization to occur, the female may temporarily halt this water flow 445 until the eggs are laid, so as to avoid washing out all the sperm, or, alternatively, the flushing out may 446 select for males that produce large ejaculates with high quality sperm. Either way, sperm competition could take place in this selection arena, with ejaculate quality, sperm quantity and time of ejaculate 448 deposition being crucial aspects of fertilization success.

449 Sex-ratio can be highly variable among D. magna populations and is known to vary strongly 450 over the season (Booksmythe et al. 2018). Consequently, the intensity of sperm competition may also 451 vary among populations and over time. When males are numerous, they must compete to fertilize the 452 oocytes in polyandrous matings. Those with the highest number of sperms remaining in the brood 453 pouch after they depart and the female lays her eggs are likely to have the highest fertilization success. 454 This would favor males who produce more sperm and who stay longer on the females. When 455 polyandrous mating is less common, it is still likely that ejaculate may evolve for higher sperm counts, 456 as sperm released in the female brood pouch can still be flushed out. In this case, the reason for the 457 selection would be sperm limitation (as defined in Liao et al., 2018), not sperm competition. In either 
case, the difference in optima for sperm count upon selection by sperm limitation or sperm competition is unknown.

As most sperm are produced early in a male's life (Wuerz et al. 2017), the total sperm count is

461 limited by the size of the spermiduct. In Daphnia, vacuoles compact the mature sperm in an extracellular process before they are released into the spermiduct to maximize the amount of stored sperm (Wingstrand 1978). Even though the sperm we observed in Daphnia medium had remained intact, it is expected that the vacuole opens in the brood pouch, eventually upon contact with the oocyte. Hence, sperm number is tightly correlated with sperm length, or at least with its compaction. length versus optimal quantity. However, if it is costly to precisely control sperm length, the variation in sperm length is predicted to correlate negatively with the intensity of sperm competition (Bauer and Breed 2006; Fitzpatrick and Baer 2011; Varea-Sanchez et al. 2014; Rowley et al. 2019). The high variance in sperm length we observed here could, therefore, indicate weak sperm competition overall. In such a case, the rod-like sperm cell does not require a strict morphology, so its shape can be more or less condensed.

Sexual selection gradient in each sex. A. J. Bateman articulated several principles explaining the undiscriminating drive of males to obtain mates versus the choosiness of females (Bateman 1948). In Daphnia, the relationship between mating success and reproductive success in females is what he calls single-mate saturation (Bateman 1948). This means that a single mating suffices to fertilize the entire clutch, so the female has no increase in reproductive success once she obtains a single mating partner. Whether or not females benefit from the male-male competition of polyandrous mating is not clear.

479 Their clutch size is unaffected; only the paternity is potentially divided between the inseminating 480 males. The sexual selection gradient in female Daphnia should therefore be weak (See figure 2 in 481 Arnold, 1994). In males, however, the expected reproductive success increases linearly with the 482 number of matings in the absence of sperm competition. For males, when polyandrous mating is 483 common, the relationship between mating success and reproductive success is what Bateman calls diminishing returns (Bateman 1948). Here, as ejaculate size diminishes with the number of matings, 
the males' competitiveness mechanically decreases too, as does the number of potential offspring gained with each additional mate (Arnold 1994). Hence, male mating success correlates linearly with reproductive success when males are proportionally less numerous than fertile females, while the correlation saturates in presence of male-male competition.

\section{Sexual selection in other cyclical parthenogenetic species.}

Although only little is known about sexual selection in other cyclical parthenogenetic species, there are reasons to believe that it plays an equally important role in these species as it does in Daphnia. In aphids, for example, the best-studied cyclical parthenogenetic species, we know that some aphid species can recognize specific mates (Guldemond et al. 1994). Also, females have been shown to release species-specific sex pheromones daily and at specific times to call males (Guldemond and Dixon 1994). These two mechanisms are used to reduce interspecific insemination and may have played a role in speciation by reinforcement in aphids (Guldemond and Dixon 1994). They could also be used by females to choose mates within the same species. Although it is known that aphids can mate for more than once and display some form of pre-copulatory stroking behavior, the occurrence of sperm competition seems unknown (Doherty and Hales 2002). Female choice is certainly possible, as females can avoid inbreeding and refuse to mate with certain males (Huang and Caillaud 2012). Together, these traits in aphids along with the example of Daphnia suggest that sexual selection

502 probably plays a role in the evolution of cyclical parthenogenetic species. Since sexual reproduction is 503 generally associated with the capacity to respond to environmental changes or dispersal, this role may

504 be more important than previously thought.

\section{Conclusion}

506 Cyclical parthenogenesis, a reproductive strategy where organisms go through several rounds of clonal

507 reproduction before reproducing sexually, is widespread in many taxa, including crustaceans, rotifers, 508 aphids, and in human parasitic nematodes. While often understudied in these species, sexual selection 509 is an important form of selection even when it is not the dominant reproductive strategy. Because the 510 sexual event occurs only after several generations of clonal reproduction, the intensity of sexual 
511 selection on sexual traits is overall reduced and the temporary absence of sexual reproduction in

512 cyclical parthenogens may give a non-negligible role to drift in the evolution of sexually dimorphic

513 traits. The reduced intensity of sexual selection may allow genetic variation to accumulate and thus,

514 enable selection to occur on multiple alleles at once. This principle is reminiscent of the first two

515 phases of Wright's shifting-balance theory (Wright 1982). Furthermore, it is likely that during clonal

516 reproduction, sexual traits (e.g. body size) may deviate from their optimal for mating/fertilization

517 success because they have different optimum under natural selection.

\section{Acknowledgements}

519 We thank Michelle Krebs and Urs Stiefel for help in the laboratory and Juergen Hottinger, Pepijn

520 Luickjx, Marjo Saastamoinen, Patrícia Beldade, Karen Haag, Andrea Hoffman, Gleb Georg Ebert and

521 Katharina Ida Ebert for help in the field. We also thank the staff at Tvärminne Zoological Station for

522 logistic support, as well as Axel Wiberg, Jeremias Brand, Vitor Faria and Eric Dexter for helpful

523 discussions. The study was supported by the Swiss National Science Foundation. DD was supported

524 by the French Laboratory of Excellence project 'TULIP' (ANR-10-LABX-41; ANR-11-IDEX-0002-

$52502)$

\section{References}

527 Altermatt, F., and D. Ebert. 2010. Populations in small, ephemeral habitat patches may drive dynamics

528 in a Daphnia magna metapopulation. Ecology 91:2975-2982.

529 Andersson, M. 1994. Sexual selection. Princeton University Press, Princeton, NJ, USA.

530 Arnold, S. J. 1994. Bateman's principles and the measurement of sexual selection in plants and

531 animals. The American Naturalist 144:S126-S149.

532 Bateman, A. 1948. Intra-sexual selection in Drosophila. Heredity 2:349-368.

533 Bauer, M., and W. G. Breed. 2006. Variation of sperm head shape and tail length in a species of

534 Australian hydromyine rodent: The spinifex hopping mouse, Notomys alexis. Reproduction, Fertility

535 and Development 18:797-805. 
536 Booksmythe, I., N. Gerber, D. Ebert, and H. Kokko. 2018. Daphnia females adjust sex allocation in

537 response to current sex ratio and density. Ecology Letters 21:629-637.

538 Brewer, M. C. 1998. Mating behaviours of Daphnia pulicaria, a cyclic parthenogen $\square$ : comparisons

539 with copepods. Philosophical Transactions of the Royal Society of London. Series B: Biological

$540 \quad$ Sciences 353:805-815.

541 Cabalzar, A. P., P. D. Fields, Y. Kato, H. Watanabe, and D. Ebert. 2019. Parasite-mediated selection

542 in a natural metapopulation of Daphnia magna. Molecular Ecology 28:4770-4785.

543 Carter, J. L., D. E. Schindler, and T. B. Francis. 2017. Effects of climate change on zooplankton

544 community interactions in an Alaskan lake. Climate Change Responses 4:1-12.

545 Cavalheri, H. B., C. C. Symons, M. Schulhof, N. T. Jones, and J. B. Shurin. 2019. Rapid evolution of

546 thermal plasticity in mountain lake Daphnia populations. Oikos 128:692-700.

547 Clutton-Brock, T. 2017. Reproductive competition and sexual selection. Philosophical Transactions of

548 the Royal Society B: Biological Sciences 372:20160310.

549 Cornetti, L., P. D. Fields, K. Van Damme, and D. Ebert. 2019. A fossil-calibrated phylogenomic

550 analysis of Daphnia and the Daphniidae. Molecular Phylogenetics and Evolution 137:250-262.

551 Cox, R. M., and R. Calsbeek. 2010. Sex-specific selection and intraspecific variation in sexual size

552 dimorphism. Evolution 64:798-809.

553 Crease, T. J., and P. D. N. Hebert. 1983. A test for the production of sexual pheromones by Daphnia

554 magna (Crustacea: Cladocera). Freshwater Biology 13:491-496.

555 Darwin, C. 1871. The descent of man, and selection in relation to sex. J. Murray, London.

556 De Meester, L. 1993. Inbreeding and outbreeding depression in Daphnia. Oecologia 96:80-84.

557 Decaestecker, E., S. Gaba, J. a M. Raeymaekers, R. Stoks, L. Van Kerckhoven, D. Ebert, and L. De

558 Meester. 2007. Host-parasite “Red Queen” dynamics archived in pond sediment. Nature 450:870-873.

559 Delignette-Muller, M. L., and C. Dutang. 2015. fitdistrplus: An R package for fitting distributions. 
561 Dixon, A. F. G. 1977. Aphid ecology: Life cycles, polymorphism, and population regulation. Annual

562 Review of Ecology and Systematics 8:329-353.

563 Doherty, H. M., and D. F. Hales. 2002. Mating success and mating behaviour of the aphid, Myzus

564 persicae (Hemiptera: Aphididae). European Journal of Entomology 99:23-27.

565 Duneau, D., P. Luijckx, L. F. Ruder, and D. Ebert. 2012. Sex-specific effects of a parasite evolving in 566 a female-biased host population. BMC Biology 10:104.

567 Duthie, A. B., and J. M. Reid. 2016. Evolution of inbreeding avoidance and inbreeding preference

568 through mate choice among interacting relatives. The American Naturalist 188:651-667.

569 Ebert, D. 2005. Ecology, epidemiology, and evolution of parasitism in Daphnia [internet]. National

570 library of medicine (US), national center for biotechnology information, Bethesda (MD).

Ebert, D., D. Duneau, M. D. Hall, P. Luijckx, J. P. Andras, L. Du Pasquier, and F. Ben-Ami. 2016. A

572 population biology perspective on the stepwise infection process of the bacterial pathogen Pasteuria

573 ramosa in Daphnia. Advances in Parasitology 91:265-310.

574 Ebert, D., C. Haag, M. Kirkpatrick, M. Riek, J. W. J. W. Hottinger, and V. I. Pajunen. 2002. A

575 selective advantage to immigrant genes in a Daphnia metapopulation. Science 295:485-488.

576 Ebert, D., J. W. Hottinger, and V. I. Pajunen. 2001. Temporal and spatial dynamics of parasite

577 richness in a Daphnia metapopulation. Ecology 82:3417-3434.

578 Fitzpatrick, J. L., and B. Baer. 2011. Polyandry reduces sperm length variation in social insects.

579 Evolution 65:3006-3012.

580 Forró, L. 1997. Mating behaviour in Moina brachiata (Jurine, 1820) (Crustacea, Anomopoda).

581 Hydrobiologia 360:153-159.

582 Garnier, S. 2018. viridis: Default color maps from "matplotlib."

583 George, D. G., D. P. Hewitt, J. W. G. Lund, and W. J. P. Smyly. 1990. The relative effects of 
enrichment and climate change on the long-term dynamics of Daphnia in Esthwaite Water, Cumbria.

585 Freshwater Biology 23:55-70.

586 Godwin, J. L., R. Vasudeva, Ł. Michalczyk, O. Y. Martin, A. J. Lumley, T. Chapman, and M. J. G.

587 Gage. 2017. Experimental evolution reveals that sperm competition intensity selects for longer, more costly sperm. Evolution Letters 1:102-113.

Goren, L., and F. Ben-Ami. 2013. Ecological correlates between cladocerans and their endoparasites from permanent and rain pools: Patterns in community composition and diversity. Hydrobiologia 701:13-23.

Guldemond, J. A., and A. F. G. Dixon. 1994. Specificity and daily cycle of release of sex pheromones in aphids: a case of reinforcement? Biological Journal of the Linnean Society 52:287-303.

Guldemond, J. A., A. F. G. Dixon, and W. T. Tigges. 1994. Mate recognition in Cryptomyzus aphids: copulation and insemination. Entomologia Experimentalis et Applicata 73:67-75. inbreeding depression in a Daphnia metapopulation. Evolution 56:518-526. Hamiltosporidium tvaerminnensis gen. et sp. nov., a microsporidian parasite of Daphnia magna, and establishment of Hamiltosporidium magnivora comb. nov. Parasitology 138:447-462.

Hahn, M. A., C. Effertz, L. Bigler, and E. von Elert. 2019. 5 $\alpha$-cyprinol sulfate, a bile salt from fish, 602 induces diel vertical migration in Daphnia. eLife 8.

606 Hebert, P. D. N., and R. D. Ward. 1972. Inheritance during parthenogenesis in Daphnia magna. 607 Genetics 71:639-642. 
analysis with estimation graphics. Nature Methods 16:565-566.

610 Hobæk, A., and P. Larsson. 1990. Sex determination in Daphnia magna. Ecology 71:2255-2268.

611 Houslay, T. M., K. F. Houslay, J. Rapkin, J. Hunt, and L. F. Bussière. 2017. Mating opportunities and

612 energetic constraints drive variation in age-dependent sexual signalling. Functional Ecology 31:728-

613741.

614 Huang, M. H., and M. C. Caillaud. 2012. Inbreeding avoidance by recognition of close kin in the pea 615 aphid, Acyrthosiphon pisum. Journal of Insect Science 12:1-13.

616 Jansen, M., A. Coors, R. Stoks, and L. De Meester. 2011. Evolutionary ecotoxicology of pesticide 617 resistance: A case study in Daphnia. Ecotoxicology 20:543-551.

618 Jiang, Y., D. I. Bolnick, and M. Kirkpatrick. 2013. Assortative mating in animals. The American 619 Naturalist 181:E125-E138.

620 Kaldun, B., and O. Otti. 2016. Condition-dependent ejaculate production affects male mating behavior 621 in the common bedbug Cimex lectularius. Ecology and Evolution 6:2548-2558.

622 Lampert, K. P. 2009. Facultative parthenogenesis in vertebrates: Reproductive error or chance? Sexual 623 Development 2:290-301.

624 Lass, S., and D. Ebert. 2006. Apparent seasonality of parasite dynamics: Analysis of cyclic prevalence 625 patterns. Proceedings of the Royal Society B: Biological Sciences 273:199-206.

626 Law, C. J., and R. S. Mehta. 2018. Carnivory maintains cranial dimorphism between males and 627 females: Evidence for niche divergence in extant Musteloidea. Evolution 72:1950-1961.

628 Lee, D., J. S. Nah, J. Yoon, W. Kim, and K. Rhee. 2019. Live observation of the oviposition process in 629 Daphnia magna. PLoS ONE 14:1-9.

630 Li, C. C., B. E. Weeks, and A. Chakravarti. 1993. Similarity of DNA fingerprints due to chance and 631 relatedness. Human Heredity 43:45-52.

632 Liao, W. B., Y. Huang, Y. Zeng, M. J. Zhong, Y. Luo, and S. Lüpold. 2018. Ejaculate evolution in 
633 external fertilizers: Influenced by sperm competition or sperm limitation? Evolution 72:4-17.

634 Lonsdale, D. J., M. A. Frey, and T. W. Snell. 1998. The role of chemical signals in copepod

635 reproduction. Journal of Marine Systems 15:1-12.

636 Lumley, A. J., Ł. Michalczyk, J. J. N. Kitson, L. G. Spurgin, C. A. Morrison, J. L. Godwin, M. E.

637 Dickinson, et al. 2015. Sexual selection protects against extinction. Nature 522:470-473.

638 Lynch, M. 1988. Estimation of relatedness by DNA fingerprinting. Molecular Biology and Evolution

$639 \quad 5: 584-599$.

640 Lynch, M., and K. Ritland. 1999. Estimation of pairwise relatedness with molecular markers. Genetics $641 \quad 152: 1753-1766$.

642 Metschnikoff, É. 1884. Über eine Sprosspilzkrank heit der Daphnien. Beitrag zur Lehre iiber den

643 Kampf der E hagocyten gegen Krankheitserreger. Virchows Archiv 96:177-195.

644 Milligan, B. G. 2003. Maximum-likelihood estimation of relatedness. Genetics 163:1153-1167.

645 Morehouse, N. I. 2014. Condition-dependent ornaments, life histories, and the evolving architecture of 646 resource-use. Integrative and Comparative Biology 54:591-600.

647 Ojima, Y. A. 1958. A cytological study on the development and maturation of the parthenogenetic and 648 sexual eggs of Daphnia pulex (Crustacea-Cladocera). Kwansei Gakuen Univ Ann Stud. 6:123-176.

649 Orlansky, S., and F. Ben-Ami. 2019. Genetic resistance and specificity in sister taxa of Daphnia:

650 Insights from the range of host susceptibilities. Parasites and Vectors 12:1-10.

651 Pajunen, V. I. 1986. Distributional dynamics of Daphnia species in a rock-pool environment. Annales 652 Zoologici Fennici 23:131-140.

653 Pew, J., P. H. Muir, J. Wang, and T. R. Frasier. 2015. Related: An R package for analysing pairwise 654 relatedness from codominant molecular markers. Molecular Ecology Resources 15:557-561.

655 Queller, D. C., and K. F. Goodnight. 1989. Estimating relatedness using genetic markers. Evolution $656 \quad 43: 258-275$. 
657 R Core Team. 2019. R: A language and environment for statistical computing. Vienna, Austria.

658 Reger, J., M. I. Lind, M. R. Robinson, and A. P. Beckerman. 2018. Predation drives local adaptation

659 of phenotypic plasticity. Nature Ecology and Evolution 2:100-107.

660 Ritland, K. 1996. Estimators for pairwise relatedness and individual inbreeding coefficients. Genetical

661 Research 67:175-185.

662 Roth, O., D. Ebert, D. B. Vizoso, A. Bieger, S. Lass, B. Annette, and S. Lass. 2008. Male-biased sex-

663 ratio distortion caused by Octosporea bayeri, a vertically and horizontally-transmitted parasite of

664 Daphnia magna. International Journal for Parasitology 38:969-979.

665 Roulin, A. C., J. Routtu, M. D. Hall, T. Janicke, I. Colson, C. R. Haag, and D. Ebert. 2013. Local

666 adaptation of sex induction in a facultative sexual crustacean: insights from QTL mapping and natural

667 populations of Daphnia magna. Molecular Ecology 22:3567-3579.

668 Rousset, F., and J.-B. Ferdy. 2014. Testing environmental and genetic effects in the presence of spatial

669 autocorrelation. Ecography 37:781-790.

670 Rowley, A., L. Locatello, A. Kahrl, M. Rego, A. Boussard, E. Garza-Gisholt, R. M. Kempster, et al.

671 2019. Sexual selection and the evolution of sperm morphology in sharks. Journal of Evolutionary

672 Biology 32:1027-1035.

673 RStudio Team. 2016. RStudio: Integrated Development Environment for R. Boston, MA.

674 Scrucca, L., M. Fop, B. Murphy, T., and E. Raftery, Adrian. 2016. mclust 5: Clustering, classification

675 and density estimation using Gaussian finite mixture models. The R Journal 8:289-317.

676 Sheikh-Jabbari, E., M. D. Hall, F. Ben-Ami, and D. Ebert. 2014. The expression of virulence for a

677 mixed-mode transmitted parasite in a diapausing host. Parasitology 141:1097-1107.

678 Shine, R. 1979. Sexual selection and sexual dimorphism in the Amphibia. Copeia 1979:297-306.

679 Shuker, D. M. 2010. Sexual selection: endless forms or tangled bank? Animal Behaviour 79:e11-e17.

680 Snell, T. W., and F. H. Hoff. 1985. The effect of environmental factors on resting egg production in 
681 the rotifer Brachionus plicatilis. Journal of the World Mariculture Society 16:484-497.

682 Springer, M. S., W. J. Murphy, E. Eizirik, and S. J. O’Brien. 2003. Placental mammal diversification

683 and the Cretaceous-Tertiary boundary. Proceedings of the National Academy of Sciences of the

684 United States of America 100:1056-1061.

685 Tollrian, R., and C. Heibl. 2004. Phenotypic plasticity in pigmentation in Daphnia induced by UV

686 radiation and fish kairomones. Functional Ecology 18:497-502.

687 Urca, H., and F. Ben-Ami. 2018. The role of spore morphology in horizontal transmission of a

688 microsporidium of Daphnia. Parasitology 145:1452-1457.

689 Varea-Sanchez, M., L. Gomez Montoto, M. Tourmente, and E. R. S. Roldan. 2014. Postcopulatory

690 sexual selection results in spermatozoa with more uniform head and flagellum sizes in rodents. PLoS

$691 \quad$ One 9:e108148.

692 Vizoso, D. B., and D. Ebert. 2005. Mixed inoculations of a microsporidian parasite with horizontal

693 and vertical infections. Oecologia 143:157-166.

694 Walsh, P. S., D. A. Metzger, and R. Higuchi. 1991. Chelex 100 as a medium for simple extraction of

695 DNA for PCR-based typing from forensic material. BioTechniques 10:506-513.

696 Wang, J. 2002. An estimator for pairwise relatedness using molecular markers. Genetics 160:1203-

6971215.

698

- 2011. Coancestry: A program for simulating, estimating and analysing relatedness and

699 inbreeding coefficients. Molecular Ecology Resources 11:141-145.

700 Ward, S. A., S. R. Leather, and A. F. G. Dixon. 1984. Temperature prediction and the timing of sex in

701 aphids. Oecologia 62:230-233.

702 Weismann, A. 1893. The germ-plasm: A theory of heredity. Charles Scribner's Sons, New York.

703 Whitlock, M. C., and A. F. Agrawal. 2009. Purging the genome with sexual selection: Reducing

704 mutation load through selection on males. Evolution 63:569-582. 
705 Wickham, H. 2016. ggplot2: Elegant graphics for data analysis. Springer-Verlag New York.

706 Wickham, H., R. François, L. Henry, and K. Müller. 2019. dplyr: A Grammar of data manipulation.

707 Wickham, H., and L. Henry. 2019. tidyr: Easily Tidy Data with "spread()" and "gather()" functions.

708 Wingstrand, K. G. 1978. Comparative spermatology of the Crustacea Entomostraca; 1, Subclass

709 Branchiopoda. Biologiske Skrifter 22:1-67.

710 Winsor, G. L., and D. J. Innes. 2002. Sexual reproduction in Daphnia pulex (Crustacea: Cladocera):

711 Observations on male mating behaviour and avoidance of inbreeding. Freshwater Biology 47:441-

712450.

713 Wolterek, R. 1909. Weitere experimentelle Untersuchungen über Artveränderung, speziel über das

714 Wesen quantitativer Artunterschiede bei Daphniden. Verhandlungen der deutschen zoologischen

715 Gesellschaft 9:110-173.

716 Wright, S. 1982. The shifting balance theory and macroevolution. Annual review of genetics 16:01-

71719.

718 Wuerz, M., E. Huebner, and J. Huebner. 2017. The morphology of the male reproductive system,

719 spermatogenesis and the spermatozoon of Daphnia magna (Crustacea: Branchiopoda). Journal of

$720 \quad$ Morphology 278:1536-1550.

721 Zaffagnini, F. 1987. Reproduction in Daphnia. Page 280 in R. H. Peters and R. De Bernadi, eds.

722 Daphnia (Vol. 45). Istituto Italiano di Idrobiologia, Pallanza.

723 Zahavi, A. 1975. Mate selection-A selection for a handicap. Journal of Theoretical Biology 53:205-

724214. 
727 Table 1: Description of the sexual process in Daphnia magna.

\section{Process}

\begin{tabular}{|c|c|c|}
\hline & $\begin{array}{l}\text { Mate } \\
\text { search }\end{array}$ & $\begin{array}{l}\text { Males search seemingly randomly for females } \\
\text { that are ready to lay sexual eggs (not } \\
\text { investigated here). }\end{array}$ \\
\hline & $\begin{array}{l}\text { Mate } \\
\text { encounter }\end{array}$ & $\begin{array}{l}\text { In some species, males seem able to follow the } \\
\text { current generated by the escaping female (not } \\
\text { investigated here). }\end{array}$ \\
\hline 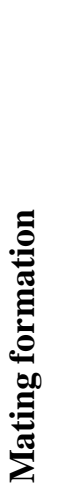 & Mounting & $\begin{array}{l}\text { There is a possibility of female choice. Males } \\
\text { are rarely found attached to asexual females. It } \\
\text { seems unlikely that males are choosy, as } \\
\text { sexually-ready females are a limited resource. } \\
\text { Females can escape males who attempt to } \\
\text { mount them. Females are found with males } \\
\text { larger than the population average and/or with } \\
\text { males that share the same infection status. } \\
\text { There is no evidence for a deviation from } \\
\text { random mating regarding genetic relatedness. }\end{array}$ \\
\hline 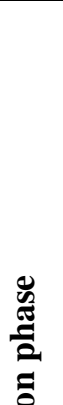 & Copulating & $\begin{array}{l}\text { Males remain attached to the female for about } \\
50 \text { min. Male-male competition may occur } \\
\text { when several males attach simultaneously to the } \\
\text { female. In this case, the male that stays on the } \\
\text { female longer is typically larger, which may } \\
\text { give it an advantage in fertilizing eggs. Sperm } \\
\text { competition may start here, but its intensity } \\
\text { depends on the frequency of polyandrous } \\
\text { mating, where one male can fertilize both eggs. }\end{array}$ \\
\hline
\end{tabular}

\section{Open question}

Do males search randomly for mating partners?

Do females actively reject males based on quality criteria?
When does ejaculation happen during the 50min. mating period?

Which male traits favor fertilization success?
By laying their sexual eggs only after the male(s) have left, females may be executing cryptic choice, as the water flow that circulates in the brood pouch (for oxygenation) may select for sperm number and quality. If the high variation in sperm length comes from the absence of a quality control mechanism, then females may select for good sperm by flushing out those that are not suitable (e.g., not able to stick on the cuticula until the egg is laid). The fact that sperm can be flushed out may also select for large ejaculates.
What happens to the sperm before the oocytes are laid in the brood pouch? 


\section{Egg}

fertilization
It likely occurs in the brood pouch, not in the oviduct, and hence is a form of external fertilization. 


\section{Figure legends}

730 Figure 1: Mating in Daphnia magna. A/ Proportion of adult males in Daphnia magna rockpool

731 populations. Based on random sampling, the proportion of males ranged from 5 to $60 \%$ with an

732 average about $30 \%$. Boxplot divides the dataset into quartiles, representing the minimum and

733 maximum, as well as the first quartile ( $25 \%$ of the dataset lies below it), the median and the third

734 quartile ( $75 \%$ of the dataset lies below it). Each grey dot represents one population, with the red dot

735 showing the arithmetic mean. B/ Photograph of a female (large individual) mating with two males

736 (small individuals). Females can mate with one (most common), two, or even three males

737 simultaneously.

739 Figure 2: A/ Role of body length in the sexual process. Mating females were $9.5 \%$ larger than

740 randomly caught females in their population. Mating males were on average $2.3 \%$ larger than

741 randomly caught males in their population. Populations showed positive assortative mating for body

742 length: males larger than the average of the population mated with females larger than the average of

743 the population. B/ Body length and mating types. Males in polyandrous mating were $0.01 \mathrm{~mm}$ smaller

744 on average than males in monandrous mating, a difference that was not statistically significant. C/

745 Body length difference of males in polyandrous matings. Males in the same mating are more different

746 than expected by chance (Paired t-test: $\mathrm{df}=97, \mathrm{t}=-0.02, \mathrm{p}=0.03$ ), with the longer-remaining males

747 being, on average, larger than the first males to detach (mean of the differences $=0.02 \mathrm{~mm}$ or $1.3 \%$ ),

748 suggesting that body length contributes to a competitive advantage in egg fertilization. The red line

749 displays zero difference.

$751 \quad$ Figure 3: Role of the parasite H. tvarminnensis in the sexual process. A/ Correlation between the

752 infection prevalence in single females in the population (i.e., proportion of infected females/total of

753 single females $)$ and in males in the population $\left(\mathrm{df}=1, \mathrm{Chi}^{\wedge} 2 \mathrm{LRT}=0.064, \mathrm{p}=1\right) . \mathrm{B} / \mathrm{Sexual}$

754 dimorphism in infection prevalence of single vs mating individuals. Prevalence differences between 
sexes depended on the mating status (Sex x Mating status: $\mathrm{df}=1$, Chi^2 $\mathrm{LRT}=17.84, \mathrm{p}=0.00002)$. On average, prevalence was higher in females than in males in the populations (left panel, $\mathrm{df}=1, \mathrm{Chi}^{\wedge} 2$ $\mathrm{LRT}=17.84, \mathrm{p}=0.00012$, odds ratio: 0.64 ), but this tendency was reversed in mating (right panel, $\mathrm{df}=1, \mathrm{Chi}^{\wedge} 2 \mathrm{LRT}=4.7, \mathrm{p}=0.03$, odds ratio: 1.4$) . \mathrm{C} /$ Prevalence in single vs mating individuals. On average, the prevalence in mating males was higher than in single males (left panel, $\mathrm{df}=1, \mathrm{Chi}^{\wedge} 2 \mathrm{LRT}$ $=17, \mathrm{p}=4.8 \mathrm{e}-5$, odds ratio: 1.8$)$. This difference was not found in females (right panel, $\mathrm{df}=1, \mathrm{Chi}^{\wedge} 2$ LRT $=0.49, \mathrm{p}=0.49$, odds ratio: 0.89 ). $\mathrm{D} /$ Assortative mating regarding infection. In mating pairs, males were infected on average 1.8 times more when the female was infected $\left(\mathrm{df}=1, \mathrm{Chi}^{\wedge} 2 \mathrm{LRT}=5.2\right.$, $\mathrm{p}=0.023$, odds ratio: 1.8). Histograms beneath the graphs are an estimation graphic as in Ho et al. (2019) using bootstrap to estimate the difference between means and its $95 \%$ confidence interval. and $* * *$ when $<0.0001$.

Figure 4: Duration of the mating process. In monandrous mating, males detached on average 24 min after they were caught, similar to the first males in polyandrous mating, which detached on average 23 min after they were caught (Wilcoxon test: $\mathrm{W}=3676, \mathrm{p}=0.99$ ). Second males detached on averaged 39 min post capture (Wilcoxon test: $\mathrm{W}=4192, \mathrm{p}=0.0002$ ). Those results suggest that mating lasted on average around $50 \mathrm{~min}$. Each dot represents a male in a mating. The y-axis is on a log scale for better illustration.

Figure 5: A/ Number of females laying eggs after male departure. B/Time between detachment of the last male and the female depositing sexual eggs; within 10 minutes for $86 \%$ (45/52) of females, and within less than 5 minutes for $\sim 40 \%$ of females. The red line represents the median. C/ Distribution of egg quantities in the ephippium from females caught in the process of mating. Numbers within brackets represent sample sizes. 
782 Figure 6: Sperm length of Daphnia magna. A/ Difference between mean ejaculates from males in the

783 same mating (first male to detach minus the second). Difference in sperm length was larger than 0.77

$784 \mu \mathrm{m}$ (i.e. $8.6 \%$ larger than the averaged sperm length) in over $50 \%$ of the cases; however, the position

785 to detach did not predict the direction of the difference, as the second male to detach was 0.96 of the

786 average of the first, a difference that was not statistically significant $\left(\mathrm{df}=1, \mathrm{Chi}^{\wedge} 2 \mathrm{LRT}=2.9, \mathrm{p}=0\right.$.

787 086). B/ Sperm length in ejaculate of males of four clones under laboratory conditions revealed more

788 variation between than within clones $\left(\mathrm{df}=3, \mathrm{Chi}^{\wedge} 2 \mathrm{LRT}=17, \mathrm{p}=6 \mathrm{e}-4\right)$, indicating a genetic

789 component of sperm length. C/ Sperm length in ejaculates of males captured from three natural

790 populations while mating ranked by median length within their ejaculate. Average standard deviation

791 within an ejaculate was $1.9 \mu \mathrm{m}$, about as large as the standard deviation of all the measured sperm, 2.2

$792 \mu \mathrm{m} . \mathrm{D} / \mathrm{Distribution}$ of sperm length in all males represented in C. Distributions within ejaculates were

793 generally better described by a Gamma than by a Gaussian distribution (or by a mixture of two

794 Gaussian distributions), excluding the hypothesis of two different morphs, with possibly different

795 functions. The inlet photograph shows sperm length variation in a typical ejaculate. 


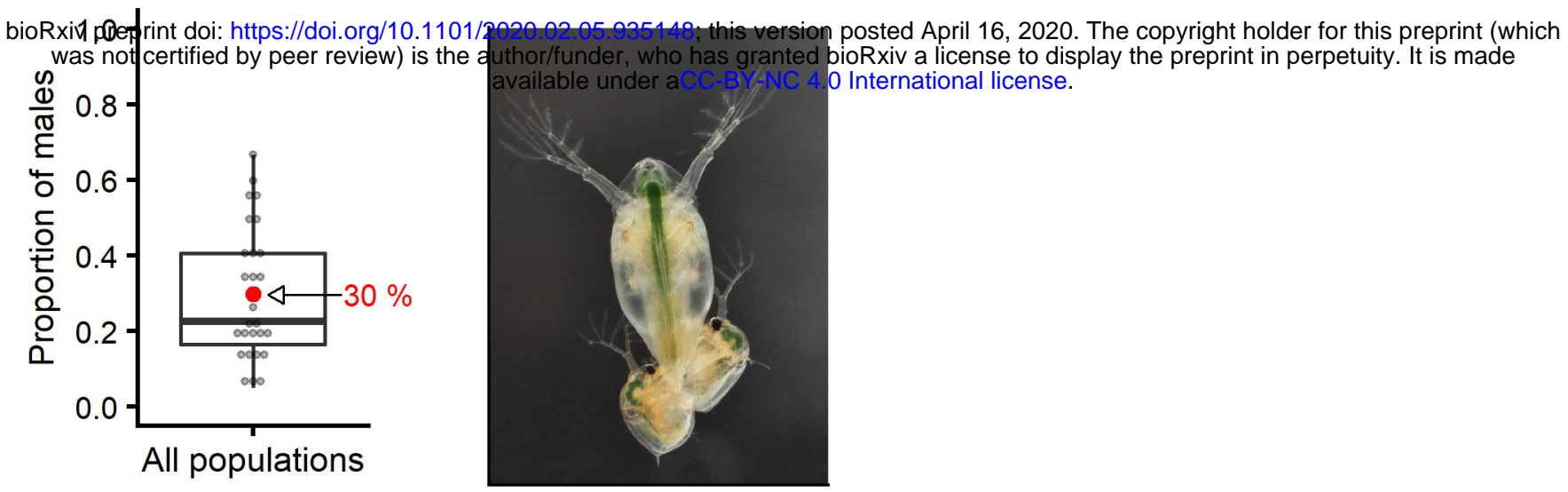

Figure 1: Mating in Daphnia magna. A/ Proportion of adult males in Daphnia magna rockpool populations. Based on random sampling, the proportion of males ranged from 5 to $60 \%$ with an average about $30 \%$. Boxplot divides the dataset into quartiles, representing the minimum and maximum, as well as the first quartile ( $25 \%$ of the dataset lies below it), the median and the third quartile (75\% of the dataset lies below it). Each grey dot represents one population, with the red dot showing the arithmetic mean. B/ Photograph of a female (large individual) mating with two males (small individuals). Females can mate with one (most common), two, or even three males simultaneously. 


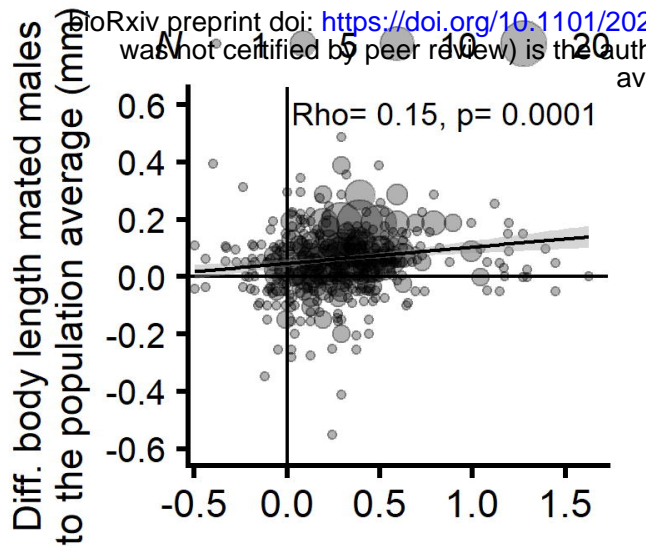

Diff. body length mated females to the population average $(\mathrm{mm})$

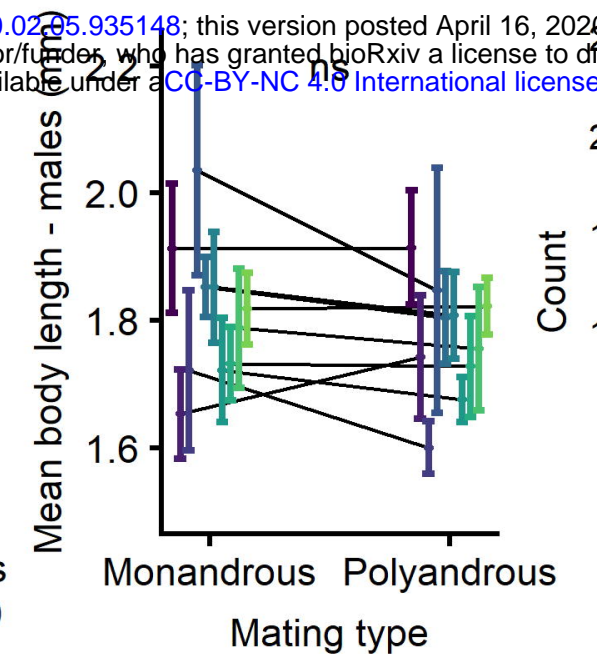

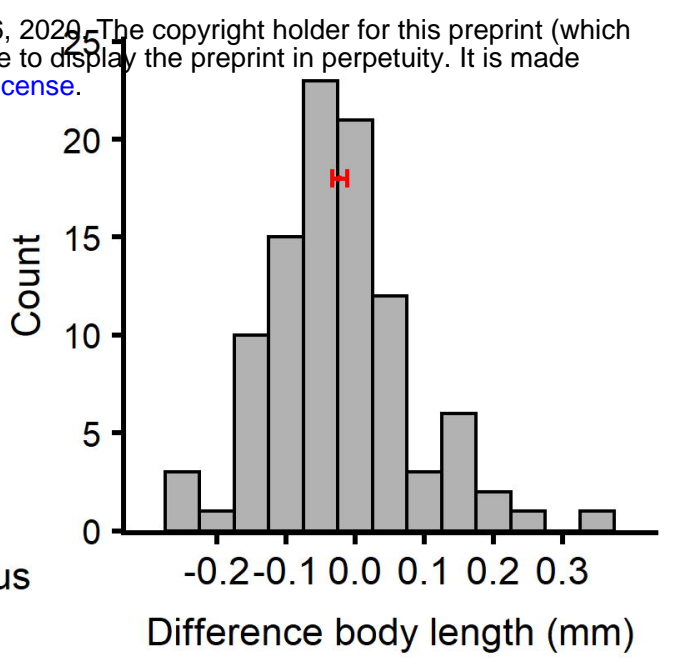

Figure 2: A/ Role of body length in the sexual process. Mating females were $9.5 \%$ larger than randomly caught females in their population. Mating males were on average $2.3 \%$ larger than randomly caught males in their population.

Populations showed positive assortative mating for body length: males larger than the average of the population mated with females larger than the average of the population. B/ Body length and mating types. Males in polyandrous mating were $0.01 \mathrm{~mm}$ smaller on average than males in monandrous mating, a difference that was not statistically significant. $\mathrm{C} / \mathrm{Body}$ length difference of males in polyandrous matings. Males in the same mating are more different than expected by chance (Paired $t$-test: $d f=97, t=-0.02, p=0.03$ ), with the longer-remaining males being, on average, larger than the first males to detach (mean of the differences $=0.02 \mathrm{~mm}$ or $1.3 \%$ ), suggesting that body length contributes to a competitive advantage in egg fertilization. The red line displays zero difference. 


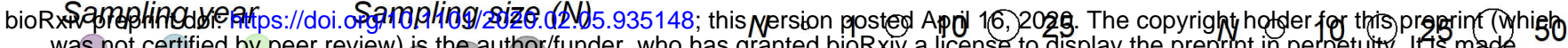
was not certified by peer review) is the author/funder, who has granted bioRxiv a license to display the preprint in perpetuity. It is made

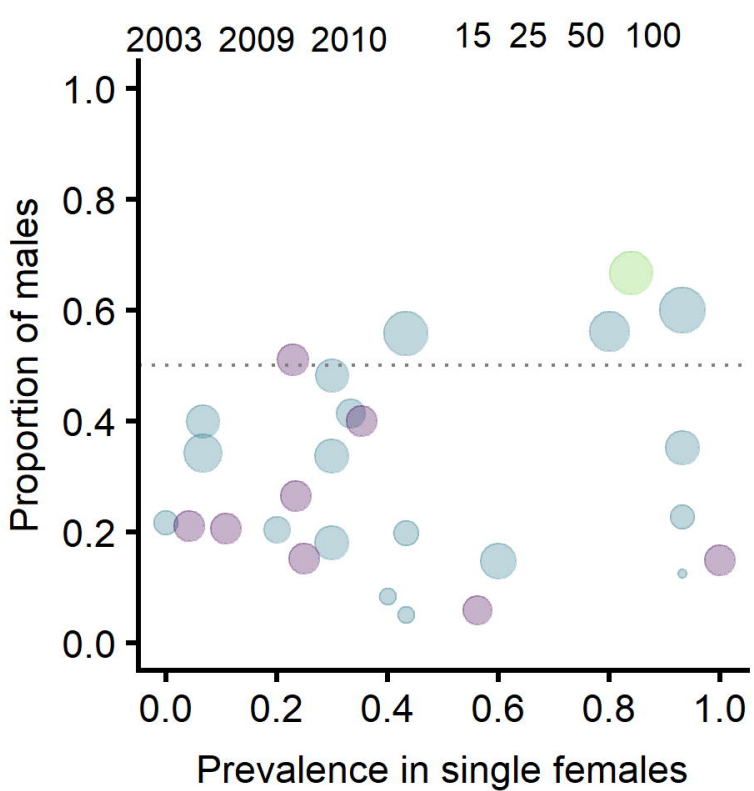

C
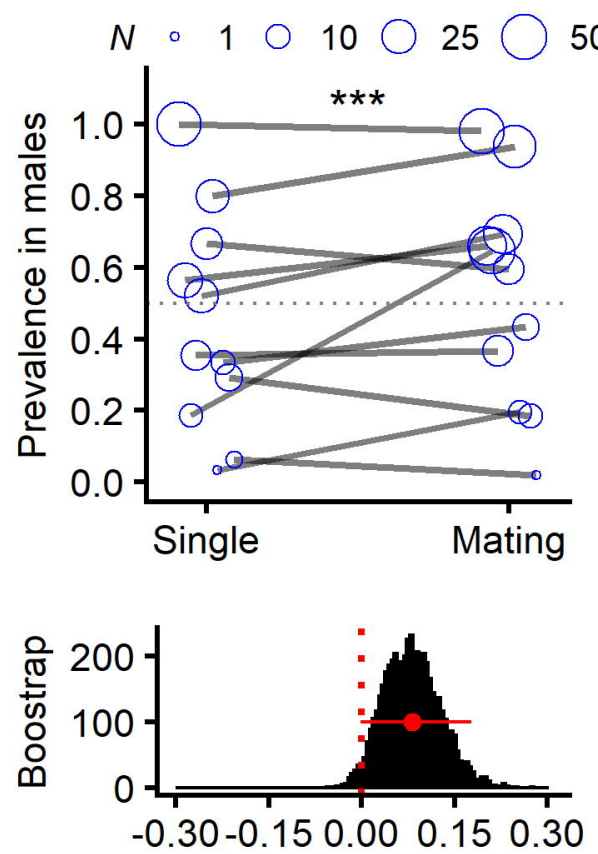

Mean differences

(Mating - Single)
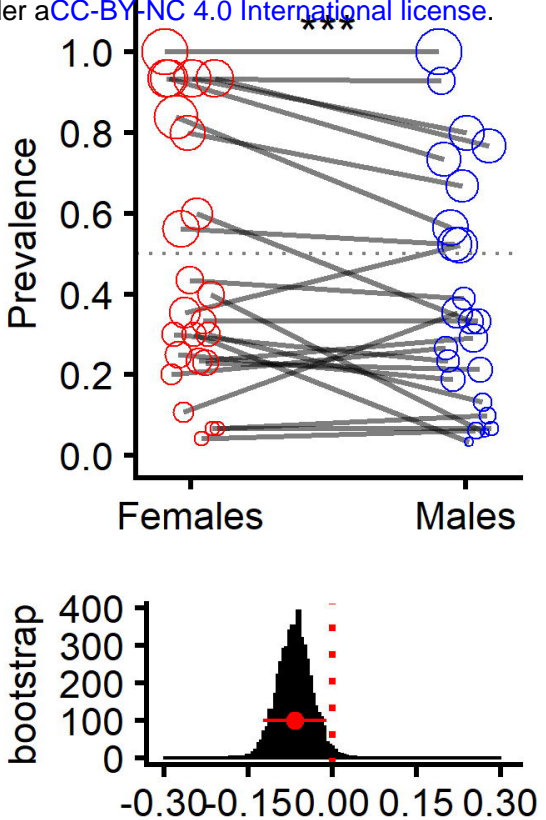

Mean differences $(\hat{o}-q)$
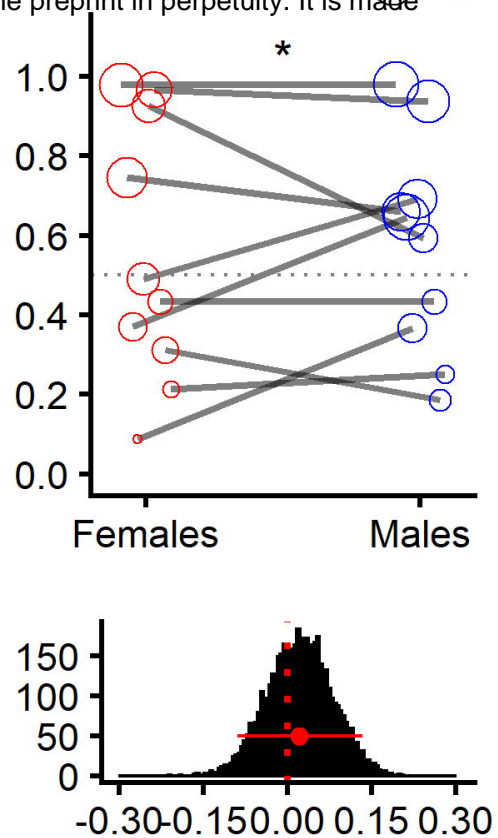

Mean differences $(\hat{\partial}-q)$

\section{Female}
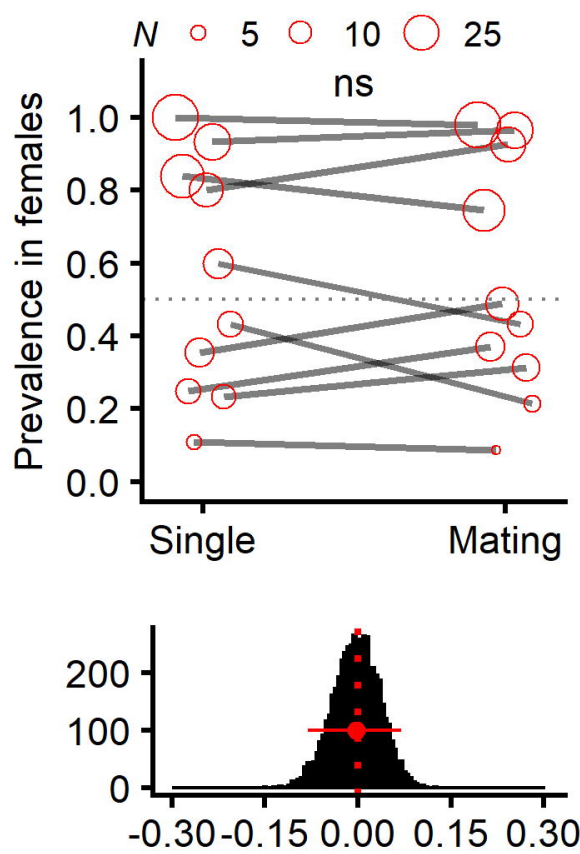

Mean differences (Mating - Single)

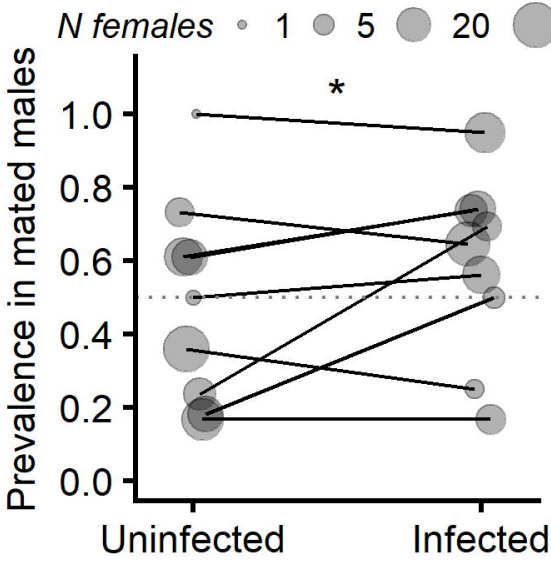

Infection status of females

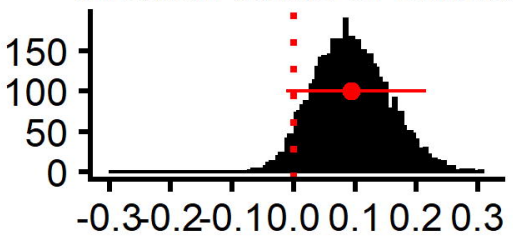

Mean differences (Inf. - Uninf.)

Figure 3: Role of the parasite H. tvarminnensis in the sexual process. A/ Correlation between the infection prevalence in single females in the population (i.e., proportion of infected females/total of single females) and in males in the population ( $\left.d f=1, C h i^{\wedge} 2 L R T=0.064, p=1\right) . B$ / Sexual dimorphism in infection prevalence of single vs mating individuals. Prevalence differences between sexes depended on the mating status (Sex $x$ Mating status: $d f=1$, Chi^2 $L R T=17.84, p=0.00002$ ). On average, prevalence was higher in females than in males in the populations (left panel, $d f=1, C h i^{\wedge} 2 L R T=17.84, p=0.00012$, odds ratio: 0.64), but this tendency was reversed in mating (right panel, $d f=1$, Chi^2 $L R T=4.7, p=0.03$, odds ratio: 1.4). C/ Prevalence in single vs mating individuals. On average, the prevalence in mating males was higher than in single males (left panel, $d f=1$, Chi^2 $L R T=17, p=4.8 e-5$, odds ratio: 1.8). This difference was not found in females (right panel, $d f=1, C h i^{\wedge} 2 L R T=0.49, p=0.49$, odds ratio: 0.89 ). $D$ / Assortative mating regarding infection. In mating pairs, males were infected on average 1.8 times more when the female was infected ( $d f=1, C h i^{\wedge} 2 L R T=5.2, p=0.023$, odds ratio: 1.8). Histograms beneath the graphs are an estimation graphic as in Ho et al. (2019) using bootstrap to estimate the difference between means and its $95 \%$ confidence interval. 


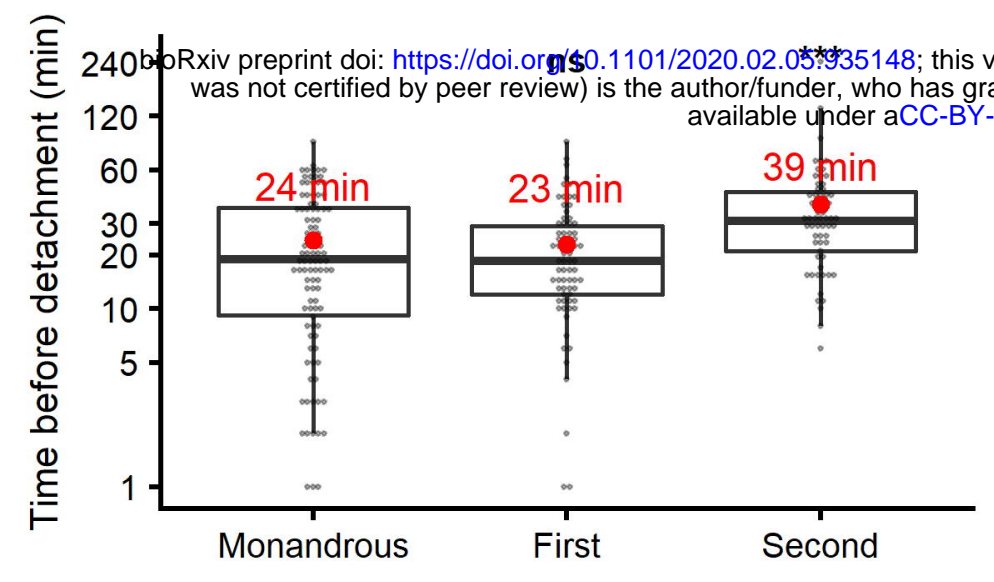

Figure 4: Duration of the mating process. In monandrous mating, males detached on average 24 min after they were caught, similar to the first males in polyandrous mating, which detached on average $23 \mathrm{~min}$ after they were caught (Wilcoxon test: $W=3676, p=0.99$ ). Second males detached on averaged 39 min post capture (Wilcoxon test: $W=4192$, $p=0.0002$ ). Those results suggest that mating lasted on average around $50 \mathrm{~min}$. Each dot represents a male in a mating. The $y$-axis is on a log scale for better illustration. 
A

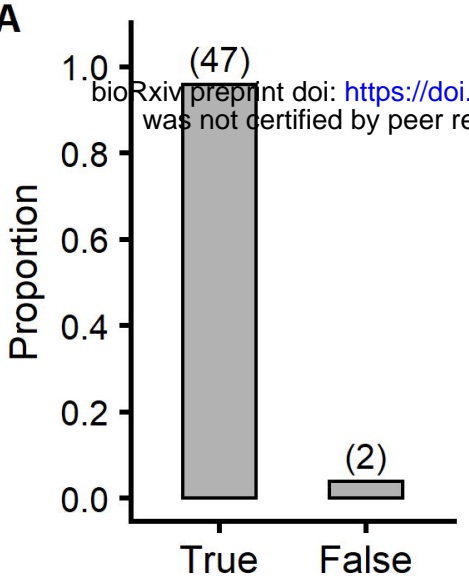

Females laying eggs after male left
B

I C

C

copyright holder for this preprin (999) the prepritht in perpetuity. It is made

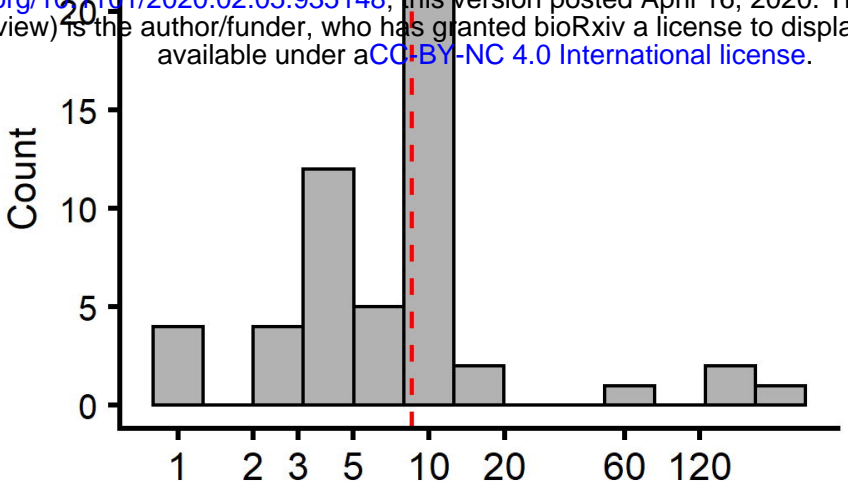

Time period from end of mating to egg laying ( $\mathrm{min})$

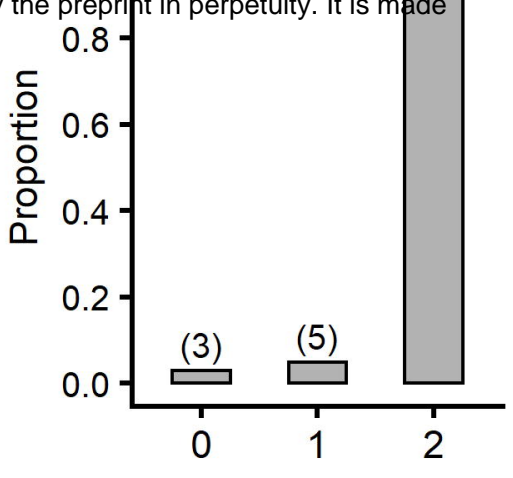

Nbr of sexual eggs in ephippium

Figure 5: A Number of females laying eggs after male departure. B/Time between detachment of the last male and the female depositing sexual eggs; within 10 minutes for $86 \%$ (45/52) of females, and within less than 5 minutes for $40 \%$ of females. The red line represents the median. C/ Distribution of egg quantities in the ephippium from females caught in the process of mating. Numbers within brackets represent sample sizes. 


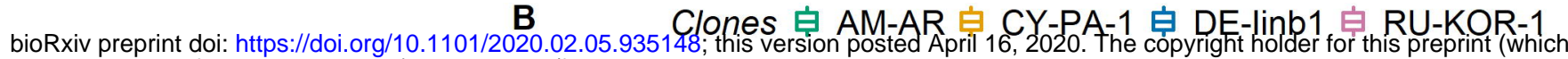
was not certified by peer review) is the author/funder, who has granted bioRxiv a license to display the preprint in perpetuity. It is made

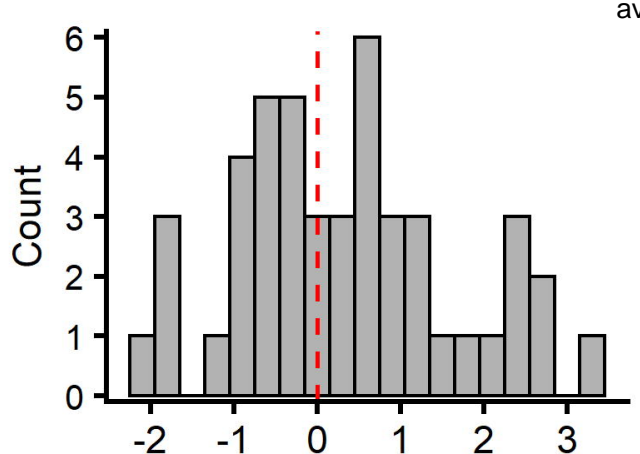

Difference mean sperm length $(\mu \mathrm{m})$ (First - second)

C

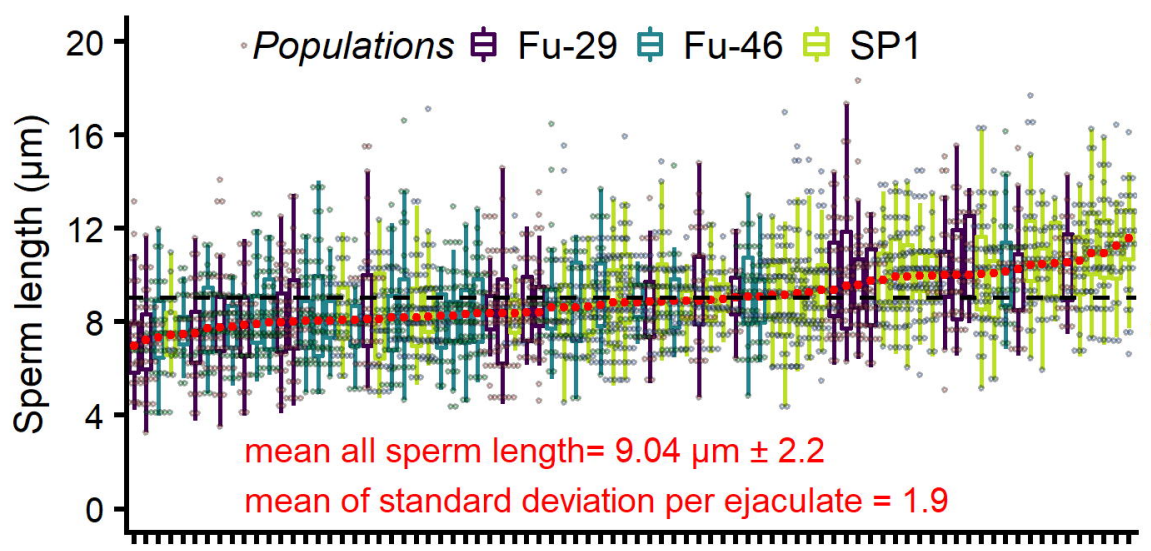

Males

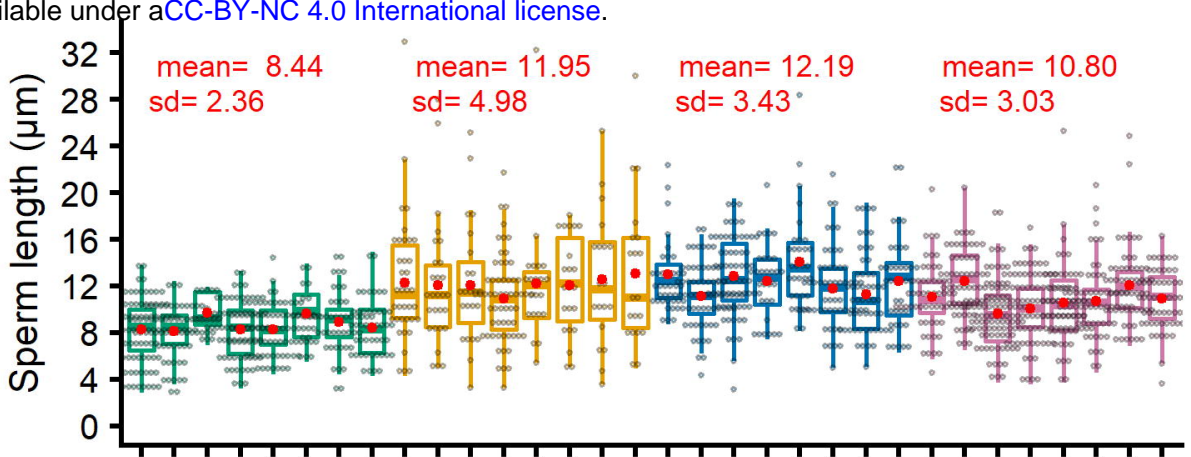

Males

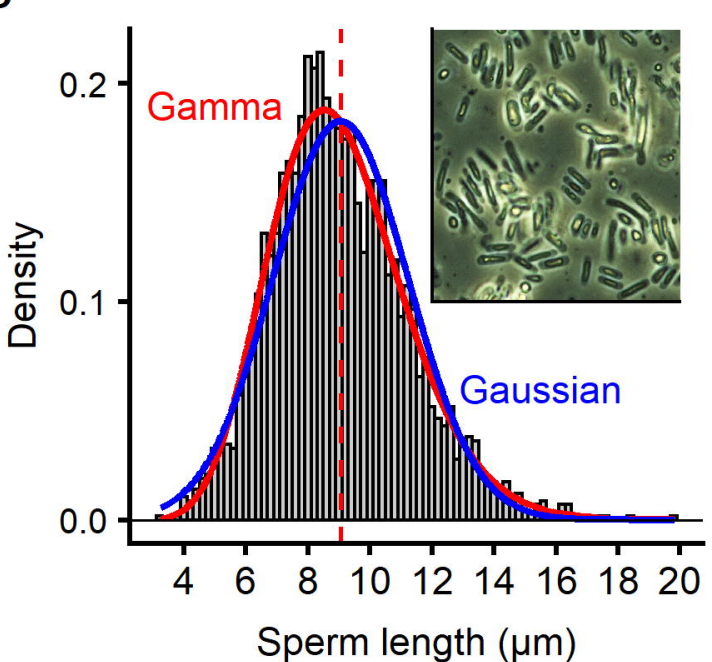

Figure 6: Sperm length of Daphnia magna. A/ Difference between mean ejaculates from males in the same mating (first male to detach minus the second). Difference in sperm length was larger than $0.77 \mu \mathrm{m}$ (i.e. $8.6 \%$ larger than the averaged sperm length) in over $50 \%$ of the cases; however, the position to detach did not predict the direction of the difference, as the second male to detach was 0.96 of the average of the first, a difference that was not statistically significant ( $d f=1, C_{1} i^{\wedge} 2 L R T=2.9, p=0.086$ ). $B$ / Sperm length in ejaculate of males of four clones under laboratory conditions revealed more variation between than within clones ( $d f=3$, Chi^2 $L R T=17, p=6 e-4$ ), indicating a genetic component of sperm length. $\mathrm{C} /$ Sperm length in ejaculates of males captured from three natural populations while mating ranked by median length within their ejaculate. Average standard deviation within an ejaculate was $1.9 \mu \mathrm{m}$, about as large as the standard deviation of all the measured sperm, $2.2 \mu \mathrm{m}$. D/Distribution of sperm length in all males represented in C. Distributions within ejaculates were generally better described by a Gamma than by a Gaussian distribution (or by a mixture of two Gaussian distributions), excluding the hypothesis of two different morphs, with possibly different functions. The inlet photograph shows sperm length variation in a typical ejaculate. 